\title{
The role of microstructure and its stability in performance of wheels in heavy haul service
}

\author{
Cong Qiu ${ }^{1} \cdot$ John Cookson ${ }^{1} \cdot$ Peter Mutton ${ }^{1}$
}

Received: 15 January 2017/Revised: 6 May 2017/ Accepted: 19 September 2017/Published online: 3 October 2017

(c) The Author(s) 2017. This article is an open access publication

\begin{abstract}
Thermal or thermo-mechanical loading is one of the major causes of wheel surface damage in Australian heavy haul operations. In addition, multi-wear wheels appear to be particularly sensitive to thermo-mechanical damage during their first service life. Such damage can incur heavy machining penalties or even premature scrapping of wheels. The combination of high contact stresses as well as substantial thermal loading (such as during prolonged periods of tread braking) can lead to severe plastic deformation, thermal fatigue and microstructural deterioration. For some high-strength wheel grades, the increased sensitivity to thermo-mechanical damage observed during the first service period may be attributed to the presence of a near-surface region in which the microstructure is more sensitive to these loading conditions than the underlying material. The standards applicable to wheels used in Australian heavy haul operations are based on the Association of American Railroads (AAR) specification M-107/M-208, which does not include any requirements for microstructure. The implementation of acceptance criteria for the microstructure, in particular that in the near-surface region of the wheel, may be necessary when new wheels are purchased. The stability of wheel microstructures during thermo-mechanical loading and the effects of alloying elements commonly used in wheel manufacturing are reviewed. A brief guide to improving thermal/mechanical stability of the microstructure is also provided.
\end{abstract}

Cong Qiu

cong.qiu@monash.edu; congqczv@gmail.com

1 Institute of Railway Technology, Monash University, Clayton, VIC 3800, Australia
Keywords Heavy haul wheels - Wheel damage · Microstructure $\cdot$ Thermal/mechanical stability $\cdot$ Alloying effect

\section{Introduction}

Axle loads used in Australian heavy haul operations currently range from 35 to 40 tonnes. Due to the ever-increasing demands of the mining industry that these operations support, axle loads may increase to even higher levels. On the other hand, tread brakes are still the primary form of train braking, coupled with the widespread introduction of electronically controlled pneumatic braking systems. The service conditions impose high contact stresses and severe thermal loads on the wheel rim. It is also well known that thermal inputs can be generated from wheel lockup (skid events), friction drag braking, traction forces, curving, hunting oscillation, etc., due to slip or creepage from wheel-rail interaction and wheel to brake block friction [1-3]. The combination of these thermal and mechanical loading conditions to the wheel rim can result in degradation or failure from one or more of the following modes:

- Thermo-mechanical shelling (TMS).

- Thermal cracking (cumulative heat input).

- Shelling from wheel skids.

Each of these degradation modes are strongly affected by the characteristics of the wheel material, the operational conditions, as well as the maintenance regimes in place.

TMS: Softening of the microstructure due to thermal loads occurs by spheroidisation of the near-surface pearlite, leading to increased sensitivity to cracking under the rolling contact loading conditions. The high-level plastic 
deformation on the wheel surface due to the combined effects of high contact stress and creepage conditions can accelerate this spheroidisation process by fracture and partial dissolution of cementite lamella in the pearlitic structure; this process is further enhanced by the increased dislocation density in the ferrite and ferrite/cementite interfaces during near-surface deformation due to accelerated carbon diffusion at dislocations [4-8].

TMS may be also sensitive to the initial microstructure. In particular, mixed microstructures (e.g. pearlite/bainite) cause problems due to the mismatch of mechanical properties at a microlevel. Figure 1 shows a typical example of TMS that caused cracking and spalling on the tread surface. The distribution of cracking reflected the combination of mechanical and thermal loading, with relatively shallow cracking present at the throat, but then quite deep cracking and spalling closer to the field side. This pattern is consistent with the findings from other studies [9-11]. Increasing the stability of the carbide phase within the microstructure, improving the hardness of wheel to minimise surface deformation and enhancing microstructure homogeneity can alleviate the incidence of TMS.

Thermal cracking: It primarily occurs due to stress cycles developed as a result of cyclic thermal loads, although under more severe thermal loads, transformation to martensite can also occur [12]. The dominant factor in terms of thermal cracking is sustained high heat input, due to the braking conditions. In terms of microstructure, the presence of bainite in the initial microstructure of the wheels has been found to increase the sensitivity to thermal fatigue damage, for example due to brake block contact towards the front rim face (Fig. 2).

Shelling from wheel skids: Small flattened surfaces (wheel flats) are formed on the wheel tread during wheel

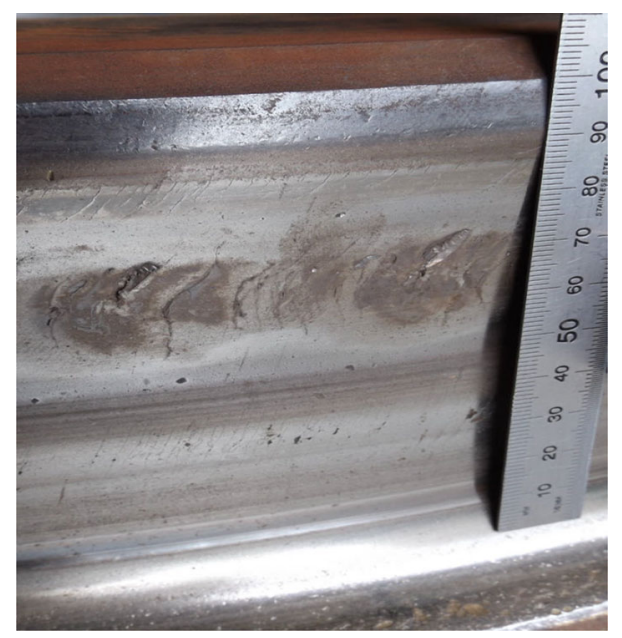

Fig. 1 Wheel tread with extensive cracking and spalling close to the field side

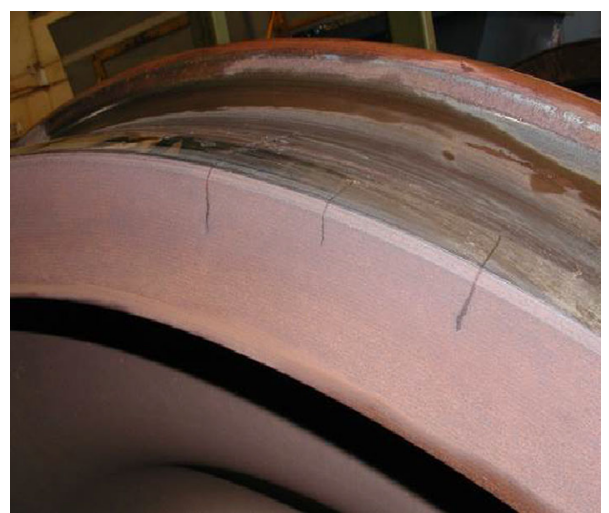

Fig. 2 Thermal fatigue cracking developed at front rim face

skid events. During the wheel flat formation, the flash heating of wheels can lead to temperatures well in excess of the austenisation temperature. The subsequent fast cooling by thermal conduction into surrounding cold metal induces martensite to form in the skid-affected area. However, the probability of martensite forming depends on the heating and cooling rates, the temperature achieved during skid evens, the effect of alloying elements on austenisation temperature and the kinetics of pearlite reaction during cooling. The combination of wheel flats and/or brittle martensite causes wheel surface cracking and even spalling (Fig. 3), which results in high-impact wheels generating high dynamic forces that are detrimental to rolling stock, rails and safety.

The main purpose of this paper is to examine the microstructural degradation in wheels in terms of the stability of the microstructure during heavy haul service, and

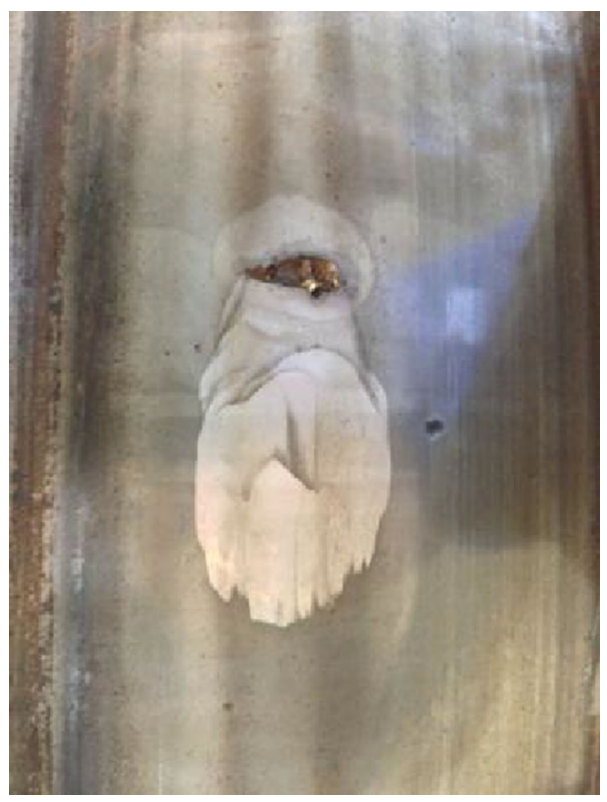

Fig. 3 Martensite and spalling around wheel flat 
the influence of initial microstructure on wheel performance. These wheels are generally manufactured in accordance with the requirements of the Association of American Railroads (AAR) [13].

The figures and results presented in the following sections are based on many years of experience in metallurgical failure analysis of wheels in heavy haul service. Since the presented results are a combination of typical examples from various such investigations, the detailed experimental and sample preparation procedures were not described here. The results are only used to assist relevant discussion.

\section{Microstructure stability}

The preferred microstructure for the wheels used in Australia heavy haul operations is pearlite; small percent of grain boundary ferrite may be present depending on the carbon content. The microstructural response of pearlite to the thermo-mechanical events outlined above is particularly important, since it determines the capacity of the material to withstand further heating and force inputs.

On cooling from the austenite during manufacture, the well-controlled chemical compositions and thermo-mechanical processing typically result in fine pearlitic microstructures. However, fine pearlite with ferrite/carbide lamellae is not very thermally stable; rather, carbide spheres in a ferrite matrix has a significantly lower free energy. Under prolonged exposure to sufficiently high temperatures, the fine lamellar structure of carbides tends to break up. This is known as "spheroidisation" of the carbide structure; this normally happens at temperatures lower than eutectoid point for wheels under service conditions. Spheroidisation of the carbide lamellae leads to a softening effect that is not predicted by testing under ambient conditions, and this can lead to reduced hardness or strength in the immediate vicinity of the wheel-rail interface. The effect of this lower strength is to allow greater metal flow, making crack formation more likely. The kinetics of spheroidisation are influenced by temperatures, accumulated exposure times, the extent of work hardening and alloying compositions. It is worth noting that severe plastic deformation at the wheel surface enhances spheroidisation by causing thinning and break-up of the lamellar carbide structure [4-8]. Simultaneously, spheroidisation allows more plastic deformation under the same level of wheel-rail loading. The spheroidisation could be a self-accelerating process during repetitive thermo-mechanical cycles. The image in Fig. 4 shows how the microstructure undergoes profound changes as a result of the combination of thermal and mechanical loading during service.

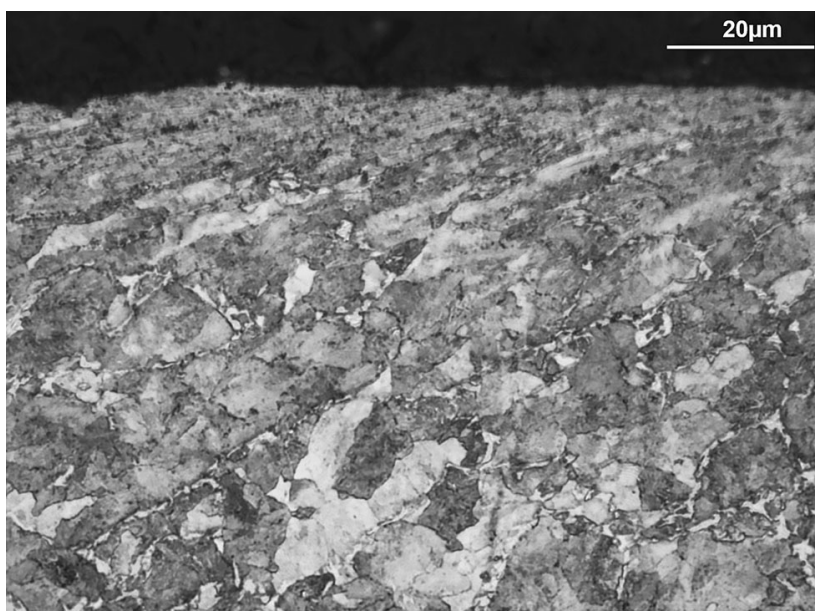

Fig. 4 Near-surface microstructure of a Class B wheel showing deformation and degradation associated with thermal loading; severely deformed pearlite was shown

On the other hand, on exposure to temperatures higher than eutectoid point, pearlite will start to transform back to a high-temperature stable phase (i.e. austenite). On cooling again under high cooling rates, the austenite could immediately transform to untempered martensite, which is very hard, very brittle and highly prone to cracking and spalling of the tread surface. Microstructural degradation during wheel skid events typically involves the re-austenitisation and subsequent martensite transformation during cooling, as illustrated in Fig. 5. However, re-austenitisation may not occur if the temperature is not high enough to exceed the austenitisation temperature. Moreover, re-austenitised region may not transfer to martensite but to bainite or back to pearlite if the cooling rate is slow relative to the kinetics of the eutectoid reaction.

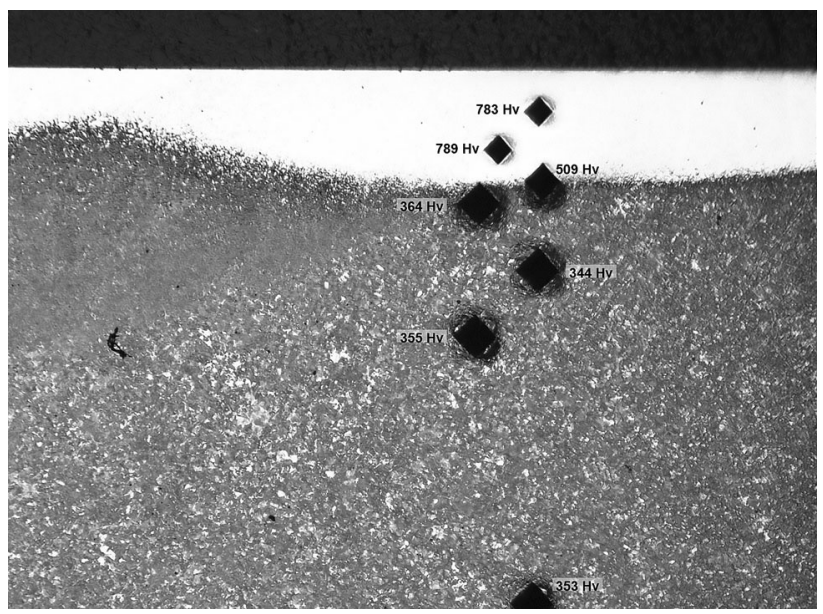

Fig. 5 Near-surface microstructure of a Class B wheel showing degradation associated with thermal loading. Martensite (bright phase), heat affected zone below martensite and pearlite matrix 
In the case of wheel skids, the cooling rate is usually high due to the quenching of the surrounding cold metal. If the temperature is high enough to cause re-austenitisation, martensite will result. The kinetics of microstructural degradation due to martensite formation are therefore determined by the kinetics of re-austenitisation during which the cementite lamellae within the pearlite are fully or partially taken into solution. The kinetics of this process are influenced by the time-temperature history during the skid event, composition and the condition of the pre-existing microstructure. For example, at elevated temperatures, the presence of carbide formers such as chromium will retard carbide dissolution [14], while carbide dissolution occurs at a greater rate in pearlitic microstructures that have sustained plastic deformation as a result of normal service conditions [2]. This is further complicated by the severe local plastic deformation, which itself can cause the dissolution of cementite [15-18]. As a result, the plastically deformed wheel surface layer may already be super-saturated with carbon during service. This layer will readily transform to martensite under a severe thermal loading event.

In summary, pearlitic microstructure in the wheel either may deteriorate as a result of cementite spheroidisation under thermo-mechanical loading events that cause intermediate temperature rise, or may lead to martensite formation at temperatures exceeding the austenitisation temperature. Improved stability of the microstructure can be achieved by retarding/avoiding spheroidisation and reaustenitisation processes. Both processes are influenced by thermal history, composition and the stored plastic deformation; among them, composition is the most accessible factor that can be tailored to enhance the pearlite stability.

\section{The effect of mixed microstructures}

Regardless of the wheel degradation modes outlined above, medium-to-high-carbon pearlitic steels are still the most popular materials for heavy haul wheels. Alternative microstructures have been considered in the literature (e.g. bainitic wheels including recent development of carbide free super-bainitic wheel steels) [19-21], but pearlitic steels still offer the best combination of stable performance, better wear rate predictability and lower cost. All of these advantages are supported by providing homogeneous pearlitic microstructure throughout the whole wheel.

The rim chill/quench process used in wheel manufacturing aims to produce fine pearlitic microstructures to improve the hardness at the rim surface. However, during this process, if the quenching conditions are not controlled perfectly, microstructures other than pearlite may be generated. Most commonly, a mixture of bainite and pearlite

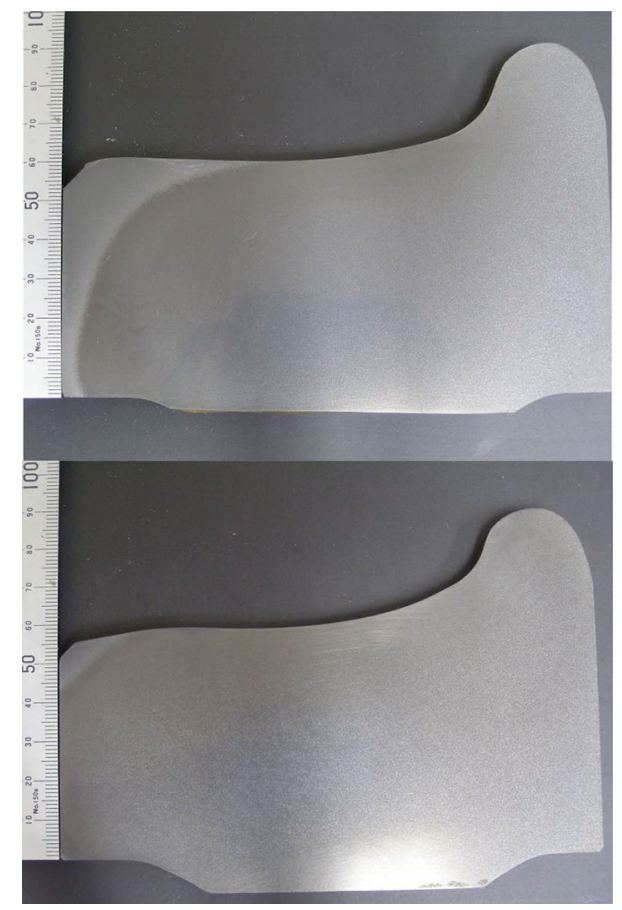

Fig. 6 Macro-section of a Class $\mathrm{C}$ wheel etched by Nital showing mixed pearlite/bainite structure at the front face rim corner indentified as lighter colour in contrast with darker pearlitic region

structure will be present on near-surface regions of the tread and flange even after final machining (Fig. 6). This mixed bainite/pearlite microstructure could have comparable hardness values with fine pearlite and therefore cannot be detected by normal rim hardness measurements at the quality control stage.

The pearlite/bainite mixture may be detrimental to wheel performance where cyclic thermo-mechanical loading is involved, for the following possible reasons:

- Pearlite and bainite have different strain hardening characteristics (i.e. a mechanical property mismatch) which may cause high local strain or stresses at the phase interface that contribute to crack initiation and propagation [22]. This is similar to the situation of dual-phase steels where ferrite and martensite coexist, which causes high local plastic strains at the interface [23-26].

- Bainite may be more thermally stable than pearlite [21]. As pearlite gradually spheroidises during service due to thermo-mechanical events, bainite may still be able to maintain its microstructural integrity. This may further increase the discrepancy of mechanical properties between the two phases and may accelerate crack initiation and propagation.

- The thermal fatigue performance may be poor due to the difference of mechanical properties and more importantly distinctly different thermal expansion and thermal conductivity [27]. 
- Last but not least, if some proportion of upper bainite is present, the large carbide particles sitting between internal boundaries of bainite could result poor wear and rolling contact fatigue (RCF) performance [21].

The detrimental factors of mixed bainite/pearlite microstructure discussed above have not been systematically studied and experimentally verified. Further investigations are required to confirm any possible causes. However, field data for multi-wear wheels in Australian heavy haul operations demonstrate that pearlitic wheels containing bainite are more sensitive to thermo-mechanical damage, especially during their first service life where the presence of bainite/pearlite mixture is most pronounced immediately below the tread surface.

One strategy for mitigating the detrimental effects of the bainitic region is to machine the surface of new wheels to limit the extent of mixed microstructures. This strategy obviously shortens wheel life, but more importantly cannot completely resolve the issue since the depth and the distribution of mixed microstructures can vary significantly, even from the same manufacturers, as shown in Fig. 6. The best approach is therefore to avoid the presence of mixed microstructure during wheel manufacturing phase through optimising both composition and heat treatment procedures.

Homogeneous pearlitic structure in the initial microstructure is considered optimal to the performance of the multi-wear wheels during their first life service. Wheels in heavy haul service in Australia are generally specified to the AAR requirements [13], with the most commonly used grades being the Class $\mathrm{B}$ with a rim hardness range of 302-341 HB and the Class $\mathrm{C}$ with a rim hardness range of 321-363 HB. In addition, microalloyed versions of both grades have been developed and are in widespread use; these provide rim hardness levels of 321-363 HB and 341-388 HB, respectively. The most recent amendments to the AAR standard include provision for an even harder wheel grade (Class D, 341-415 HB), with composition complying with the requirements for Class $\mathrm{C}$ wheels. Mixed pearlite/bainite can already exist in Class $\mathrm{C}$ wheels; more aggressive quenching conditions used to manufacture Class D wheels can result in wheels which exhibit more extensive regions of non-pearlitic microstructure than are typically present in current wheels.

In the AAR standard, there is no requirement for initial microstructure. Based on the adverse effects of mixed microstructure in the as-manufactured condition on the performance of first-life multi-wear wheels discussed above, the importance of initial microstructure needs to be emphasised and the implementation of acceptance criteria regarding the initial microstructure may be necessary when new multi-wear wheels are purchased. On this basis, a requirement for the examination of the initial microstructure to ensure homogeneous pearlitic microstructures is suggested. The influence of the initial microstructure on the first service life of multi-wear wheels will also need to be further investigated against the service conditions in different heavy haul systems.

\section{The effect of alloying elements}

The presence of the alloying elements in wheel steels serves two purposes: (1) promoting the formation of fine pearlite during manufacturing and (2) retarding microstructure deterioration during thermo-mechanical events under service conditions.

The pearlite structure can be refined by increasing the undercooling which allows the austenite to pearlite transformation to start at lower temperatures. Increased undercooling not only increases the thermodynamic driving force for phase transformation but also limits the carbon diffusion distance; both of these aid the formation of finer pearlite.

In terms of microstructural degradation, the long-term spheroidisation of carbide at intermediate temperatures can be slowed down by retarding carbon redistribution. However, the benefit of sluggish carbon diffusion is considered to be fairly limited for rapid heating and cooling cycles such as under wheel slip conditions, since the martensitic regions are usually formed at the outmost surface layer where the material is severely plastically deformed. Carbon diffusion is accelerated in the deformed layer; moreover, the deformation develops a carbon-saturated layer due to partial or even full dissolution of cementite [15-18]. This layer may transform to martensite once the re-austenitisation temperature is reached. It appears the best way to decrease the tendency for martensite formation during skid events is therefore to raise the re-austenitisation temperature or to encourage the re-austenitised region to transform back to pearlite during cooling.

Ideally, the combined effects of the selected alloying elements in wheel materials should simultaneously increase undercooling and transformation kinetics during pearlite formation, retard carbon redistribution and raise reaustenitisation temperature. Unfortunately, these requirements cannot all be fulfilled at the same time. The most conflicting aspect is between the acceleration of pearlite formation and the other three.

The presence of alloying elements significantly affects the phase transformation kinetics. At the atomic level, almost all the commonly used alloying elements (with the exception of cobalt, which is too expensive to be considered in steel wheels) tend to delay the transformation to pearlite and allow the austenitic structure to persist to lower 
temperatures during cooling. This is equivalent to increasing undercooling. Since the effect of these alloying elements is essentially to retard carbon redistribution, the solute additions used to delay pearlite transformation also slow down the spheroidisation process. Another way to further increase the undercooling is to add elements that raise eutectoid temperature, so a higher driving force is provided at a same given temperature. Coincidently, the increased eutectoid temperature serves the same purpose as increasing re-austenitisation temperature that reduces martensite formation tendency. Due to these common features, the selection of alloying compositions should aim to delay pearlite transformation and raise eutectoid temperature. It is emphasised again that delay and acceleration of pearlite transformation cannot be achieved together by manipulating alloying elements.

Alloying elements tend to fall into three groups: (1) carbide forming elements such as chromium, molybdenum, vanadium and niobium, (2) those elements that stabilise austenite and decrease eutectoid temperature including manganese and nickel, and (3) ferrite stabilisers which increases eutectoid temperature, such as silicon and aluminium. The roles of specific elements used in wheel materials in general terms were described in detail previously [28].

Apart from the commonly used alloying additions addressed above, the role of sulphur is worth particular mention. The requirement in the AAR specification is for a minimum sulphur content of $0.005 \%$ (and a maximum of $0.040 \%$ ). Steels with lower hydrogen levels can now be produced by improved steelmaking technology, and wheel materials containing lower sulphur levels and improved toughness are now available. However, reducing the sulphur level may result in a slight increase in the effective manganese level, which may not only increase the tendency for martensite formation during wheel skid events, but also contributes to higher hardenability and hence may increase the depth of non-pearlitic regions in the initial microstructure. Machinability of higher strength wheel material grades may also be adversely affected by lower sulphur levels, due to a reduction in the level of $\mathrm{MnS}$ inclusions. The balance between manganese and sulphur for wheel materials containing lower sulphur levels may need to be carefully tuned to address these issues.

Combing the views expressed in this paper and the key information delivered in [28], an alloying combination containing chromium and silicon should be used to refine pearlitic structure and increase pearlite stability. Manganese and nickel should be tailored such that embrittlement due to sulphur is removed but not intended to lower eutectoid temperature; additionally, manganese and sulphur contents should be well balanced to ensure proper initial microstructure and machinability. A small amount of vanadium and niobium is also beneficial for rolling contact performance. Suitable concentration of molybdenum could be included to further enhance pearlite stability.

\section{Conclusions}

Wheels used in heavy haul operations are subjected to service conditions which involve a combination of mechanical and thermal loads, and it is the combination of these conditions which must be considered when specifying wheel material grades. The wheels should contain homogeneous pearlitic microstructures that are thermally stable and suitable for the intended service conditions.

The presence of mixed pearlite/bainite microstructures in the near-surface region of the rim in multi-wear wheels appears to be the major factor that increases the sensitivity to thermo-mechanical damage during the first service life. Alloy designs and rim quenching conditions should therefore be optimised to avoid the formation of mixed microstructures. The alloy design should also facilitate the generation of fine pearlite and enhancement of microstructural stability during thermo-mechanical events. The exact alloy levels should be tailored through experiments and verified by on-site trials.

Acknowledgements This paper is partly based on metallurgical examination of wheel damage arising from a combination of mechanical and thermal loading under heavy haul and freight operations. The authors acknowledge the support of the Australian railway industry for these activities.

Open Access This article is distributed under the terms of the Creative Commons Attribution 4.0 International License (http:// creativecommons.org/licenses/by/4.0/), which permits unrestricted use, distribution, and reproduction in any medium, provided you give appropriate credit to the original author(s) and the source, provide a link to the Creative Commons license, and indicate if changes were made.

\section{References}

1. Cvetkovski K (2012) Influence of thermal loading on mechanical properties of railway wheel steels. Department of Materials and Manufacturing Technology, Materials Technology, Chalmers University of Technology, Göteborg

2. Cvetkovski K, Ahlström J (2013) Characterisation of plastic deformation and thermal softening of the surface layer of railway passenger wheel treads. Wear 300:200-204

3. Lewis R, Olofsson U (2009) Wheel-rail interface handbook. Elsevier, Amsterdam

4. Arruabarrena J, Uranga P, Lopez B et al (2012) Carbide spheroidization kinetics in a low-alloy, medium-carbon steel: relevance of deformation after transformation. Iron Steel Technol 9:122-128

5. Lv ZQ, Sun SH, Wang ZH, et al (2008) Effect of alloying elements addition on coarsening behavior of pearlitic cementite 
particles after severe cold rolling and annealing. Mater Sci Eng A 489:107-112

6. Nikas D, Ahlström J, Malakizadi A (2015) Mechanical properties and fatigue behavior of railway wheel steels as influenced by mechanical and thermal loadings. In: 10th International conference on contact mechanics of wheel/rail systems, CM 2015

7. Cvetkovski K, Ahlström J, Karlsson B (2011) Thermal degradation of pearlitic steels: influence on mechanical properties including fatigue behaviour. Mater Sci Technol 27:648-654

8. Chattopadhyay S, Sellars CM (1982) Kinetics of pearlite spheroidisation during static annealing and during hot deformation. Acta Metall 30:157-170

9. Moyar GJ, Stone DH (1991) An analysis of the thermal contributions to railway wheel shelling. Wear 144:117-138

10. Tournay $\mathrm{H}$ (2010) A root cause for thermal mechanical fatigue resulting in high impact wheels. In: 16th International wheelset congress

11. Tournay $H$ (2012) Wheel/rail rolling contact fatigue under $32 t$ axle load freight operation in North America. In: 9th International conference on contact mechanics and wear of rail/wheel systems, CM 2012. Southwest Jiaotong University, Chengdu

12. Ekberg A, Kabo E (2005) Fatigue of railway wheels and rails under rolling contact and thermal loading-an overview. Wear 258:1288-1300

13. Association of American Railroads (2010) Wheels, carbon steel, manual of standards and recommended practices, specification M-107/M-208

14. Sawley KJ (2007) Calculation of temperatures in a sliding wheel/ rail system and implications for wheel steel development. Proc Inst Mech Eng Part F J Rail Rapid Transit 221:455-464

15. Li YJ, Choi P, Borchers C et al (2011) Atomic-scale mechanisms of deformation-induced cementite decomposition in pearlite. Acta Mater 59:3965-3977

16. Hono K, Ohnuma M, Murayama M et al (2001) Cementite decomposition in heavily drawn pearlite steel wire. Scr Mater 44:977-983

17. Basirat M, Fredriksson $H$ (2013) An insight into the effect of deformation on carbide dissolution in the band structure of bearing steel. In: 8th International conference on diffusion in solids and liquids mass transfer-heat transfer-microstructure and properties-nanodiffusion and nanostructured materials, DSL 2012. Trans Tech Publications Ltd, Istanbul

18. Umemoto M, Todaka Y, Ohno A et al (2006) Dissolution of cementite in carbon steels by heavy deformation and laser heat treatment. In: 3rd International conference on nanomaterials by severe plastics deformation, NanoSPD3, Fukuoka

19. Zhang M, Qian J, Gu H (2007) The structure stability of carbidefree bainite wheel steel. J Mater Eng Perform 16:635-639

20. Zhang MR, Gu HC (2007) Microstructure and properties of carbide free bainite railway wheels produced by programmed quenching. Mater Sci Technol 23:970-974

21. Bhadeshia HKDH (2001) Bainite in steels: transformations, microstructure and properties. IOM Communications, London

22. Yasuda K, Sueyoshi H, Ishikawa N et al (2015) Strain hardening and plastic instability of dual-phase steels for strain based design. In: 25th International ocean and polar engineering conference, ISOPE 2015. International Society of Offshore and Polar Engineers

23. Ghassemi-Armaki H, Maßß R, Bhat SP et al (2014) Deformation response of ferrite and martensite in a dual-phase steel. Acta Mater 62:197-211

24. Fallahi A, Khamedi R, Minak G et al (2012) Monitoring of the deformation and fracture process of dual phase steels employing acoustic emission techniques. Mater Sci Eng A 548:183-188

25. Calcagnotto M, Adachi Y, Ponge D et al (2011) Deformation and fracture mechanisms in fine- and ultrafine-grained ferrite/martensite dual-phase steels and the effect of aging. Acta Mater 59:658-670

26. Korzekwa DA, Lawson RD, Matlock DK et al (1980) A consideration of models describing the strength and ductility of dualphase steels. Scr Metall 14:1023-1028

27. Park JH, Kweon YG, Kim HJ et al (2000) Effects of alloying elements on thermal fatigue and thermal shock resistance of the HSLA cast steels. ISIJ Int 40:1164-1169

28. Cookson J, Mutton P (2014) Performance of wheels in heavy haul service-matching microstructures to service conditions. In: Conference on railway excellence. Melbourne, Australia 